\title{
EXPLORING THE LEARNING AND TRAINING DIMENSION OF A DIGITAL PLATFORM FOR TERRITORY-BASED INNOVATION
}

\author{
F. Ramos, L. Pedro, A.M. Pisco Almeida, P.A. Silva \\ University of Aveiro, DigiMedia (PORTUGAL)
}

\begin{abstract}
The CeNTER-Community-led Territorial Innovation research programme aims at developing interdisciplinary research towards a comprehensive understanding of trade-offs on territory-based innovation models based on the engagement of citizens and communities, with a special focus in the context of the Portuguese Centro region. The research work, presently starting its third and final year, includes the design and laboratorial validation of a digital platform, currently being prototyped. This paper discusses the learning and training dimension that such platform shall have, aiming at offering services to users, according to their platform's usage behaviour and pattern. The following sections include an introduction to the CeNTER research programme and a brief overview of the research methodology adopted. Based on the findings of the research conducted so far, the paper then discusses, the (hyper)mediation role of the CeNTER digital platform on territory-based innovation.
\end{abstract}

Keywords: learning and training, territory-based innovation, digital platform, mediation.

\section{INTRODUCTION}

The CeNTER-Community-led Territorial Innovation research programme (http://center.web.ua.pt) was established in 2017 at the University of Aveiro, Portugal, as a result of the recognition of the need to address research on policy and tools aiming at promoting the engagement of citizens and communities in the valorisation of territorial endogenous resources, in order to improve employment and quality of life in the Centro region of Portugal. In this programme, a multidisciplinary research team [1], that includes experts of Territorial Innovation, Tourism, Management and Economics, Tourism, Psychology, and Communication Sciences and Technologies, was created and is working towards achieving specific targets:

- Identifying best practices and case studies of territorial innovation that can potentially be transferred to the Portuguese context, especially the Centro region;

- Understanding the impact of a smart specialization strategy in regional innovation efficacy;

- Understanding the role of communities and community networks in territorial innovation systems;

- Proposing tools and initiatives to leverage community-led innovation strategies and foster communities' collaboration and engagement;

- Proposing measurement tools for territorial innovation that will enable the understanding of the main differences in terms of innovation within a geographical context at the NUT II and III levels.

After two years of research work, and now starting the third and final year under the current funding framework, CeNTER has already produced research evidence addressing several of these goals [2], [3], [4].

One of the specific results expected from CeNTER is the thorough understanding of the role digital media in leveraging community-led innovation strategies and fostering communities' collaboration and engagement. For such purpose, extensive research has been conducted aiming at defining the features a digital platform should make available to territory-based innovation agents. One of the key findings of this study was the identification of the potential of a digital platform, primarily designed to foster innovation-oriented mediation, to also include features addressing specific learning and training users' needs, detected from their behaviour and usage patterns in the platform.

The next sections briefly present the research work developed so far, the main findings of the data collection phase that led to the concept underpinning of the CeNTER digital platform, and a discussion, based on several use cases, of the potential of the platform to provide learning and training services. 


\section{METHODOLOGY AND MAIN FINDINGS}

The research methodology adopted in CeNTER in order to understand best practices, case studies, the roles of communities and community networks and the power of digital media to foster territory-based innovation, included secondary and primary data collection. As far as the secondary sources are concerned, a systematic literature review was developed, using the SCOPUS database, covering the publishing period 2016-2018. Using as selection criteria keywords addressing the use of digital media for community-led and territory-based innovation, only six papers were identified that met those search criteria [5], [6], [7], [8], [9], [10]. The analysis of these papers revealed that the approach to the use of digital platforms for territory-based innovation, included both open social media platforms as well as specific platforms. However, those platforms were limited to a passive role, i.e., basically sharing of user registered data when requested by explicit search actions.

Primary data collection was held through a set of semi-structured interviews and focus groups with the participation of innovation agents, representatives from social, cultural and economic sectors, active in the Centro region of Portugal. The analysis of these primary data showed that innovation agents aspire for an independent active mediation role that should - autonomously - generate opportunities (notifications and recommendations) for cooperation, aiming at increasing the competitiveness of the different businesses, social clusters, and territories. This means that the role of a digital platform shall not solely be a passive one, offering just a bridge between agents and conveying data previously delivered about their identity and activities, but shall take a much more active role offering an (hyper)mediation service that aims at fostering connections and interactions among agents.

Another interesting finding from the primary data collection based research was that territory-based innovation agents already use a plethora of communications services (including mobile telephony and several of the more popular social media applications, such as Facebook, Instagram, and Twitter) and they are not keen to add new specific communication platforms to those set of services and devices.

\section{THE CeNTER PLATFORM}

The concept for the CeNTER platform developed from the findings of the multi-layered research conducted and briefly described in section 2 . As a result, the CeNTER digital platform shall offer three core categories of features: data registration and sharing; communication; and mediation. Figure 1 shows the main components of the CeNTER platform.

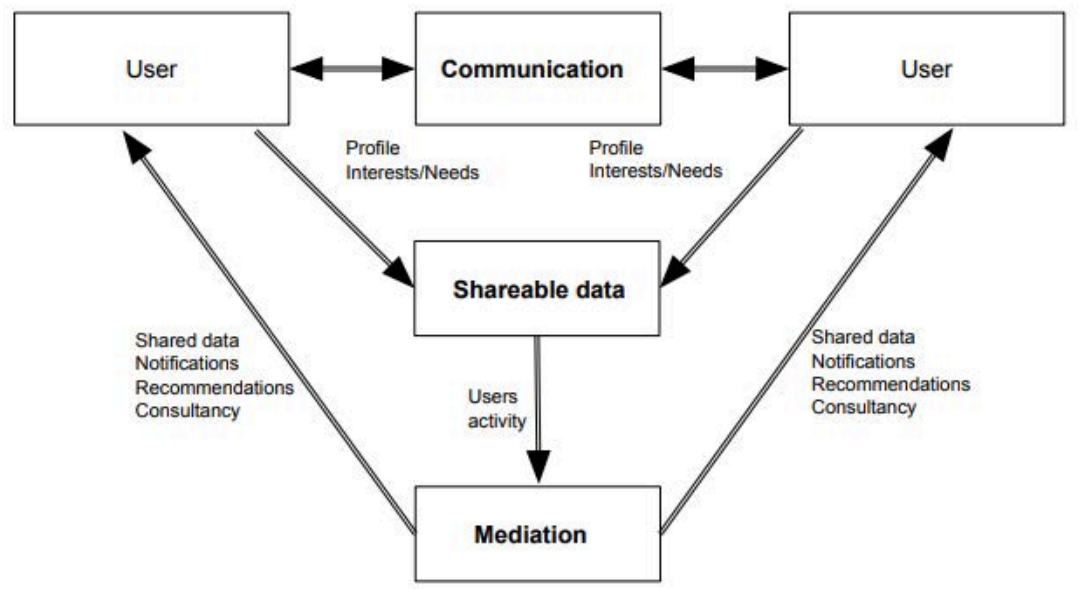

Figure 1. Main components of the CeNTER platform.

The data registration and sharing category includes the basic features allowing user's registration (user's profile, interests and needs) and activities' registration. Activities are time bound actions that a specific user promotes, individually or in collaboration with other users.

Because potential users stated that they were not willing to be overloaded with new communication tools, the communication features shall be endorsed on a very basic approach and offering connections to other communication platforms. 
The uniqueness of the CeNTER platform emerges out of a set of differentiating features that shall support and be based on a mediation function. Mediation shall offer each user a continuous flow of notifications and recommendations, which are triggered according to her/his declared interests and needs. The flow of notifications and recommendations may be further complemented by the data and communication details detected in other users' profiles, whose activities, interests and needs are similar to those of the user. Features based on this mediation function require advanced algorithms based on the users' profile and also on users' long-term dynamics, comprising a level of complexity close to the one that influenced the concept of hypermediation [11].

With a view to fully support hypermediation, the CeNTER platform shall also provide users with consultancy. Consultancy shall offer support to the user, whenever a potential weakness or inconsistency in the use of the platform is identified. Such consultancy view paves the way for the learning and training dimension of the platform, that will be further explored in the next section.

\section{EXPLORING THE LEARNING AND TRAINING DIMENSION OF THE CENTER PLATFORM}

The learning and training opportunities can be generated in the CeNTER platform from indicators related to the usage profile of the platform's users and can be valuable in many different scenarios where users may be facing difficulties. Examples of typical scenarios that may trigger learning and training consultancy are: improving the level of proficiency on the use of the platform; sharing good practices for effective networking on territory-based innovation; building capacity on how to create effective communication strategies; making suggestions on specific topics detected based on the user interaction patterns; improvement of language skills.

The next subsections address each of these use cases' examples.

\subsection{Improving the level of proficiency on the use of the platform}

Users experiencing difficulties using the platform's features, shall be offered with a context-oriented training proposal aiming at helping them overcome those apparent difficulties. The algorithm to detect this type of difficulties shall analyse usage patterns from each specific user, and problems shall be identified whenever a user recurrently fails to complete typical navigation patterns, such as: exceeding a predefined time threshold to browse information about new users or activities; not reacting to notifications or recommendations; failing to complete the registration procedure; not using the platform for a predefined time.

\subsection{Sharing good practices for effective networking on territory-based innovation}

Different entities will use the platform in different ways in order to achieve different territory-based innovation results. All the actions on the platform can be analysed and typified (such as the steps that were taken to build the network, the type and frequency of interactions that took place, the communication modes that were used, etc.) and thus be suggested to other entities with similar objectives, initiating similar actions in the platform. By providing this feature, the platform is establishing a catalogue of good practices for specific purposes that can be suggested to guide future users. Having mediation as its core feature, the CeNTER platform may also suggest specific activities identified as key and strategic in strengthening ties among territory-based innovation agents. In line with this, and for instance, having detected a pattern that is focused mainly on browsing entities, the system may suggest the organization of a networking event.

\subsection{Building capacity on how to create effective communication strategies}

The cross analysis of usage patterns and declared objectives by entities in the platform can also be used to provide recommendations related to the use of digital media to better design specific communication strategies related with initiatives or events. These recommendations can take the form of suggestions of other platforms and tools, of training modules offered by other entities registered in the platform, or of contact to other entities that had similar ontological paths in the platform. 


\subsection{Affording focus on specific search topics}

Whenever a recurrent focus on specific search topics is identified, according to a predefined threshold, the platform shall propose, if available, access to learning and training materials or opportunities (e.g. tutorials, courses) provided by other users. If, for example, a user recurrently searches the topic "National Parks", if learning/training materials or opportunities related to this topic are available (e.g.: what is a national park; good practices when visiting national parks; learning about science topics in national parks; species in danger in the national parks; pedagogic activities for children in national parks), the user shall be offered the chance to access those materials.

This function paves the way for an open marketplace for sharing learning and training resources and opportunities including sharing access to open educational resources (OER) and suggestions of specific learning programmes.

\subsection{Supporting the improvement of language skills}

Recurrent typing mistakes or lexical errors shall drive the possibility for users to be offered language learning materials aiming at helping to improve their language skills. This functionality shall be very useful to users who are not native speakers of the languages supported by the platform and shall be offered on a context-oriented basis. For example: if a user recurrently fails to write "Centro region", information about the administrative organisation of Portugal will help avoiding further similar errors.

\section{CONCLUSIONS}

Extensive research on territory-based innovation practices conducted within the CeNTER programme revealed the yet passive current status of the typical use of digital media in the mediation process among innovation agents. Furthermore, findings from research also clearly indicate that users are not willing to engage with new communication services that could add to the already existing plethora of services they are currently familiar. These findings where pivotal to the founding idea underlying the design of the CeNTER platform, that is focused on the hypermediation concept. Hypermediation in this context comprises the active promotion of awareness and connections among the platform users, based on their profile, interests and needs, also taking in account the long run users' dynamics on the platform.

Hypermediation shall be implemented through notifications, recommendations and consultancy. The learning and training dimension of the platform, that shall be triggered whenever a user reveals weaknesses or some inconsistency in the use of the platform, shall offer users the chance to improve their skills and capacities, thus contributing to enhance their role as territory-based innovation agents.

\section{ACKNOWLEDGEMENTS}

The Research Programme "CeNTER - Community-led Networks for Territorial Innovation" (CENTRO01-0145-FEDER-000002) is funded by Programa Operacional Regional do Centro (CENTRO 2020), ERDF, PT2020. The authors also acknowledge a very special recognition to the CeNTER programme research team.

\section{REFERENCES}

[1] B. Godejord, A. M. Pisco Almeida, F. Ramos, "Collaborative knowledge practice in a project work context: from challenges to knowledge media strategies" in Proceedings of the EDULEARN 2018 Conference, 6033-6041, IATED, 2018.

[2] A. Polido, S. Pires, C. Rodrigues, F. Teles, "Territorial innovation models in less developed regions: a review" in Proceedings of the 24th International Sustainable Development Research Society Conference, ISDRS, 2018.

[3] F. Brandão, C. Costa, "Evolution of innovation theory and practice: from firms to the territory " in Creativity, entrepreneurship and absorptive capacity: endogenous aspects of territorial innovation, 17-48, Italy: Aracne, 2018.

[4] P. Silva, O. Tymoshchuk, D. Renó, A. M. Almeida, L. Pedro, F. Ramos, "Unravelling the role of ICT in regional innovation networks: a case study of the music festival Bons Sons" in The Interplay of Data, Technology, Place and People for Smart Learning, 47-61, Springer, 2018. 
[5] M. Martiskainen, E. Heiskanen, G. Speciale, "Community energy initiatives to alleviate fuel poverty: the material politics of Energy Cafés", Local Environment, vol 23, no 1, 20-35, 2018.

[6] T. Schoor, H. Lente, B. Scholtens, A. Peine, "Challenging obduracy: how local communities transform the energy system", Energy Research \& Social Science, vol. 13, 94-105, 2016.

[7] M. Ferrari, C. Jong, V. Belohrad, "Community-based monitoring and information systems in the context of the Convention on Biological Diversity", Biodiversity, vol. 16, no. 2-3, 57-67, 2015.

[8] I. Pohjola, A. Puusa, "Group dynamics and the role of ICT in the life cycle analysis of community of practice-based product development: a case study", Journal of Knowledge Management, vol. 20, no. 3, 465-483, 2016.

[9] D. Thapa, Ø. Sæbø, "Participation in ICT development interventions: who and how?", Electronic Journal of Information Systems in Developing Countries, vol 75, no. 1, 2016.

[10] S. Bonomi, F. Ricciardi, C. Rossignoli, "Network organisations for externality challenges: how social entrepreneurship co-evolves with ICT-enabled solutions", International Journal of KnowledgeBased Development, vol. 8, no. 4, 346-366, 2017.

[11] C. Scolari, "From (new)media to (hyper)mediations. Recovering Jesús Martín-Barbero's mediation theory in the age of digital communication and cultural convergence", Information, Communication and Society, vol. 18, no. 9, 2015. 